\title{
Record gift to University of Toronto faculty of medicine supports Al, equity
}

\author{
— Cite as: CMAJ 2020 October 13;192:E1223-4. doi: 10.1503/cmaj.1095900
}

Posted on cmajnews.com on September 24, 2020

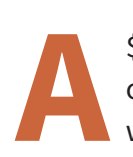

\$250-million gift to the University of Toronto's faculty of medicine will support artificial intelligence (Al), biomedical research and collaboration, and equity efforts. The investment also includes $\$ 10$ million for the dean's COVID-19 priority fund announced earlier this year.

The university says the donation is the largest ever in Canadian philanthropy. In recognition, the school will name the faculty of medicine and a new medical building funded by the gift after donors James and Louise Temerty.

"Their gift will touch every aspect of our programs, impacting education, research and clinical care across the region and round the globe," says Dr. Trevor Young, dean of the newly christened Temerty Faculty of Medicine. "It will allow us to respond nimbly to exciting research and partnership opportunities as they arise and lead the way to big medical breakthroughs."

Among other initiatives, the money will fund the creation of a new centre for Al research and education led by Muhammad Mamdani, vice president of data science and advanced analytics at Unity Health Toronto.

The centre will bring together experts in medicine, computer science and statistics to advance Al training, research, and infrastructure in health care. "Al is very much a team sport," Mamdani says. "The centre offers a focal point for all of these different disciplines to come together and form that team."

Innovations in machine learning and health care are already happening "in pieces" across the university's community, Mamdani says. For example, St. Mike's recently launched an early warning system that uses Al to predict which internal

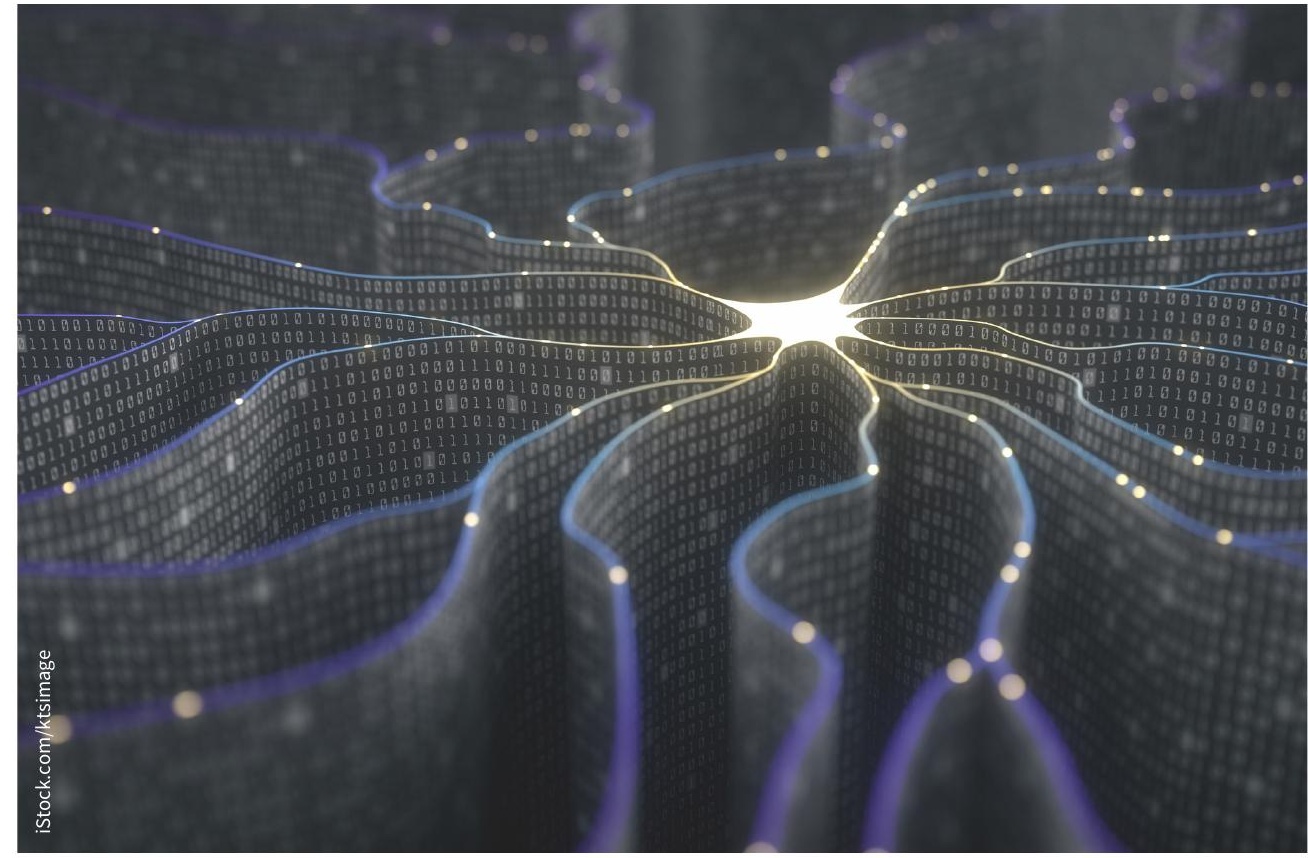

A new centre for artificial intelligence will bring together experts in computer science, statistics, and medicine.

medicine patients will die or require intensive care within 24-48 hours. Meanwhile, researchers at SickKids have developed algorithms that can predict cardiac arrest in the pediatric population.

Working together, these teams could "build things that are even more powerful," Mamdani says. The Temerty gift will also fund the creation of a shared "data environment" - essentially, a repository of datasets that researchers, educators, and students can use collaboratively.

Beyond the Al centre, the money will support a fund for collaboration across partner hospitals in the Toronto Academic Health Science Network, as well as a fund for strategic initiatives and innovations to allow the university to invest in star researchers, equipment and programs as opportunities arise.
According to Dr. Patricia Houston, vice dean of medical education, the university will further invest in wellness and equity initiatives for medical learners and faculty, particularly those who are Black and Indigenous. "We know that we don't have a perfect learning environment," she says. "We're all learning about things such as implicit bias, allyship and microaggressions and their impact on the learning and work environment."

To that end, the faculty of medicine will increase outreach programs and financial aid for underrepresented students, establish an Elder in residence and circle of Elders to support Indigenous people working with the faculty, and ensure Indigenous health education and leadership is "supported in perpetuity." 


\section{What's in a name?}

Houston says the \$250-million gift from the Temerty Foundation is "transformational," surpassing the $\$ 200$-million gift given to McGill University by John and Marcy McCall MacBain in 2019.

Medical institutions have increasingly sought out "naming" gifts in recent decades as they have become more reliant on philanthropy as an essential source of funding. Some of these gifts have proven controversial, raising questions about undue influence and whether a donor's political or business background matters in philanthropy.
Houston says the faculty of medicine's decision to adopt the Temerty name "demonstrated our gratitude for their investment." Naming gifts also shows "the importance of philanthropy to others," she says.

James Temerty, who founded the green energy company Northland Power, said he and his wife hoped to help the University of Toronto to "elevate quality health care and ultimately help as many Canadians as possible."

Through their charitable foundation, the couple have supported the creation of the Temerty Centre for Therapeutic Brain
Intervention at the Centre for Addiction and Mental Health, the Louise Temerty Breast Cancer Centre at Sunnybrook Health Sciences Centre, and the world's first international tele-simulation centre in medical education at University Hospital Network.

According to Houston, the University of Toronto has clear guidelines around donations that protect autonomy and academic freedom. The faculty of medicine set its strategic plan before reaching out to potential donors, she explains. "We will not and cannot accept any influence."

Lauren Vogel, CMAJ 